\title{
Elastic Standard Academic Credit System and Practice ${ }^{1}$
}

\author{
Lu Wang ${ }^{2}$ Hong Zhang ${ }^{3}$ Rupeng Lin ${ }^{4}$ Jun Hu$^{5}$
}

Jinan University, Guangzhou, Guangdong Province, 510632

\begin{abstract}
In the context of the internationalization of education, the implementation of the credit system has become the consensus of the higher education sector. At present, various types of credit systems including the Complete Academic Credit System, the Annual Credit System and the Grade Point Average System, etc. are widely implemented in mainland's universities. In this paper, the unique Elastic Standard Academic Credit System is introduced. Within the system, the standard credit value is based on the learning requirements of different disciplines and the cognition capability of the student group, allowing elasticity in the quantitative valuation in the individual learning capability variation with scientific manner. The system has been implemented in Jinan University for seven years and generated positive effect. It successfully keeps a good balance between The Complete Credit System and Annual Credit System, which meets the practical needs of China's national condition and has importance significance for the implementation of academic credit system in China's higher education.
\end{abstract}

Keywords: Standard Credit System, Elastic Credit System, Complete Electives System, Systemized and Modularized Curriculum System

The academic credit system is also known as academic credit accumulation system, which is a teaching management system which measures the learning capacity of students with accumulated credits, as well as an education model which meets the needs of students' personality development with selective learning content and flexible study hours. The academic credit system originated from the Harvard University in the United States at the end of 19th century. Since then, it has been gradually improved in numerous renowned universities. The system was first introduced to China in 1919 and later rolled out in 1929. However, it was suspended from 1952 till the 1980s. Since the 1990s, domestic universities started to widely implement the academic credit system. Some directly referred to foreign experience, some implemented the annual credit system and GPA system, while some made explorative trials, among which the Elastic Standard Academic

\footnotetext{
1.Project funding: Exploration and Practice of Undergraduate Education Model Reform In the Context of International Students. The Research Project on Guangdong Higher Education Teaching Reform BKWT2011003

2.Senior Staff Member, Division of Academic Affairs, Jinan University

3.Professor \& Division Head, Division of Academic Affairs, Jinan University

4.Vice President, Jinan University

5.President, Jinan University
}

(C) 2013. The authors - Published by Atlantis Press 542 
Credit System adapted by Jinan University is an example of innovative and unique credit systems.

\section{Definition and Connotation of the Elastic Standard Academic Credit System}

The Elastic Standard Academic Credit System determines the standard credit value based on the learning requirements of different disciplines and the cognition capability of the student group, allowing elasticity in the quantitative valuation in the individual learning capability variation with scientific manner.

The connotation is as follows:

Complete Electives Systems + Standard Academic Credit System + Elastic Variation System

\subsection{Complete Electives System.}

The Elastic Standard Academic Credit System adopts the Complete Electives System and all the courses can only be taken when the student select them, that is, the learning time of the compulsory courses, the types and time of the selective courses are all self-chosen by the students according to their learning requirements, abilities and interests. Meanwhile, they can keep the course sequence through technical setup. In the complete system, the student training plans vary from person to person which meets the need of the requirement of individualized development and ensure the completeness of the knowledge structure.

\subsection{Standard Credit System.}

The required standard credit value is set up according to the whole students' group cognitive ability every academic year (every term). In Jinan University, a 4year undergraduate student needs to earn the total 160 credits to graduate with 20 credits for each term; a five-year under- graduate medical student needs to earn the total 240 credits, with 24 credits for each term. The Standard Credit System can effectively distribute a reasonable study load for the student in each term avoiding the student's fallacious arrangement in the Complete Electives System which can lead to the study load misdistribution.

\subsection{Elastic Standard Academic Cred- it System}

This is an elastic variation of the Standard Credit System including two parts, (i) a $10 \%$ elastic rising of the compulsory standard credit value every term; (ii) a suitable variation for of the compulsory standard credit value according to the student's academic situation which can be concretely explained that one more credit can be earned with the grade point between 3.0-3.4; two more credits can be earned with the grade point between 3.53.9; three more credits can be earned with the grade point over 4.0. The student can also choose to earn the credits below the compulsory standard requirement but no less than 15 credits every term. According to the above standard, a controllable elastic educational system (3.5-5.5 years) can be achieved.

\section{The Implementation Measure of the Elastic Standard Academic Credit System}

\subsection{Building a Perfect Managing Op- eration Technical Platform for the Elastic Standard Academic Credit System}

The operation of the credit system cannot be separated with the technical support of credit system managing operation. The implementation of Complete Electives System, Elastic Credit System and other systems under the operation of the Elastic Standard Credit System has raised a 
higher standard for the management of the credit system. The managing technical support is required to achieve the setup of the sequence of the courses in The Electives System, students' selecting courses according to the variation of the grade points and the students' elimination management. Through the research and development of the "Comprehensive Education Management System", Jinan University set up an advanced managing operation technical platform for the Elastic Standard Academic Credit System thoroughly includes educational management parts such as the setup of the talent training system, school management, course management, course arrangement and scheduling, academic early-warning system and graduate audit system, which achieved the efficient operation of the Elastic Standard Academic Credit System management system.

\subsection{Establishing a Systemized and Modularized Curriculum System}

The development of the credit system relies on the gradual perfection of the curriculum system and the gradual scientization of the curriculum provision. The precondition of the implementation of the Elastic Standard Academic System is to reform the traditional Electives System which uses the teaching mode of unified course timetable in a major-unit or in a class-unit. This sets up a high requirement of the courses, that is, the quantity needs to meet the students' requirements, the quality needs to cover the cultivation fields of knowledge, ability and talent quality and the formation of Systemized and Modularized Curriculum System to achieve the mutual complementation of the selective courses and compulsory courses and the coordination of the curriculum modules. Since 2009, Jinan University optimized the curriculum system to establish a curriculum systematic framework which is liberal education courses, basic education courses and professional education courses intercoordinated according to the "target"-"knowledge", "ability requirement""courses" design idea under the guidance of the target to finally form a distinctive "target-oriented" curriculum system suitable for the integrated development of the students comprehensive quality.

\subsection{Deepening the Elective System: "The Complete Electives Sys- tem"}

The essence and soul of the credit system is the elective system which acts as a precondition and basis of the implementation of credit system. Some elective systems still require the students to select the courses according to the teaching plan or just let them self-select a fraction of courses, resulting in the lack of flexibility and autonomy in the learning and a great discount in the function that the credit system needs to meet the requirement of students' individualized development. In the Elastic Standard Academic System, the elective system must be deepened to give a full play. Jinan University implements the Complete Electives System that only the selected courses can be attended including the compulsory courses and selective courses to let the students select the content and length of both the compulsory and selective courses according to their own learning requirements, abilities and interests, which, shows a great respect to the requirement of individualized development. At the same time, the system is divided into two phases: preselection and cancelling and re-selection. Through these phases, the students are allowed to have an audition and they can cancel and re-select if unsatisfied with the courses, and the selection of lecturers is achieved. 


\subsection{Improving the Tutorial System}

After the inheritance and development of the credit system in more than a hundred years, the function of tutorial system is testified and cannot be replaced. It is a great assurance of the smooth operation of other structural elements of the credit system and the credit system without the guarantee of the tutorial system is incompact. The implementation of the tutorial system can make the students have general systematical cognition and build reasonable knowledge systems purposefully in a planned way. Especially referring to the Elastic Standard Academic System in which the students can overall plan their study arrangement even the study length according to the study rate of progress, abilities and interests, the guidance of the tutors can be more important. Jinan University built a total set of undergraduate supervisor system including selecting, evaluation and awarding to let the students have the "study guidance", "mind guidance" and "direction guidance", instructing them to select the courses, to deal with the quantity and quality of the learning, to design a learning access with a reasonable knowledge structure and can let them fully develop the individualities and specialties.

\subsection{Carrying out the Elimination Sys- tem Strictly}

The elimination system is a natural selection in the credit system, a must for the effective operation of credit system, a key link to achieve the talent cultivation target and ensure the quality, also an important guarantee for the elastic credit system (3.5-5.5 academic years). Hence, the elimination system must be carried out strictly to implement the Elastic Standard Academic System. Jinan University carries out the humanized elimination system through a combined "process assessment (academic warning system) + summative assessment (graduation verification system)" method to regularly persuade the students who don't earn the required minimum credits in two continuous terms to quit every academic year.

\section{The Practice Effect and Experience of the Elastic Standard Academic System}

At the moment, the Elastic Standard Academic System has been carried in Jinan University for 7 years and has been acted as a dominant teaching management system for over 20,000 students. The 7 years practice has proved that this system is very suitable for Chinese education which can take full advantage of the credit system in the higher education administration.

\subsection{The Elastic Standard Academic System Is an Up-to-date Choice Based on Reality}

Due to the selectivity of the contents, the elasticity of the length and the flexibility of the course assessment, the credit system broke the traditional "one set fits all" mode and can help the students raise the learning initiative and positivity, help the teachers tailor the teaching approach accordingly, bring out the teachers' best, accelerate the knowledge spreading and updating speed, help build an education mode fit for the students' individual characteristics, respect the differences between each students to satisfy the personality development requirements and help promote the talent cultivation quality substantially. The implementation of credit system has become the consensus in the higher education institutions. However, from the perspective of the development, the formation of the credit system itself is a gradual history process, and also a cultural evolution. Each country's unique culture and history background, the varia- 
tion of social society development, and the differences of school-running scale and pattern can all influence the concrete implementation of credit system. Therefore, the implementation should proceed from the reality, keep pace with the times combining the situation of our country and constantly seek for development. Jinan University carried out a trial implementation from the 1978 revival and never stopped seeking development. After 5 years trial (1978 1983), the credit system was carried out completely in 1983 and after 3 years (1983 1985), the grade point average system was tested in 1985 , the complete academic credit system was tested in 1992 and the Standard Credit System was tested in 1993. The implementation of the Standard Credit System avoided the waste of resources and the falling of the learning quality. Given that this system lacked some elasticity, the Elastic Standard Academic Credit System was tested in 2006 and was a beneficial choice based on reality and up-to-date.

\subsection{The Elastic Standard Academic Credit System achieved the bal- ance between the Complete Aca- demic Credit System and the An- nual Credit System.}

The Complete Academic Credit System and the Annual Credit System are two main systems in the higher education. The former is to calculate the study load in credits which allows the students to graduate achieve the enough credits while the latter is to combine the annual system with credit system, which have a concrete requirement for the compulsory credits on the basis of class teaching and is not flexible with only a small range of selective courses not allowing graduate ahead of the schedule. Both of these two systems have the advantages and disadvantages. On one hand, in the Complete Academic Credit System, the elasticity meets the requirement of personnel development and the quantity of the selective courses enriches the students' knowledge but the over-flexible system cannot ensure the study quantity or may cause the waste of education if the student postpones the graduation unlimitedly, besides, the freeselected courses may not be a complete knowledge structure and cause a fall in the learning quality. On the other hand, the Annual Credit System avoids the over-elasticity yet lacks the flexibility and the respect of personnel development which is not good for the improvement of the students' cultivation and loses the significance of the credit system.

The Elastic Standard Academic Credit System took the advantages of the Complete Academic Credit System and the Annual Credit System avoiding the relevant disadvantages and kept balance between these two systems. (1) The Elastic Standard Academic Credit System regulated the loads and process of the learning and "tempered justice with mercy". The required standard credits value was set up to ensure the reasonable learning loads and allowed elasticity to achieve a controllable elastic schooling system (3.5-5.5 academic years). For one thing, it achieved the respect for the difference of the students' learning abilities which could hardly achieved in the Annual Credit System, and the students could have the flexibility, motility to develop individually; for another, it also had a macro control of the whole university training to avoid the misdistribution of learning loads in four years that could seriously influence the learning effect or the length of the academic years which short time could not ensure the learning quality and long time may cause the education resources waste. (2) The Elastic Standard Academic Credit System took the Complete Electives System. The students can choose the compulsory and selective courses according to their own learning requirements, abilities and interests. In 
this system, every student could have their specific training system which showed respect to the personnel development. Meantime, through the setup of the "Systemized and Modularized Curriculum System" and the technical support to ensure the sequence of the selected courses, the student's fallacious arrangement in the Complete Electives System could be avoided and the reasonable knowledge structure and ability structure could be built easily.

\subsection{The Elastic Standard Academic Credit System meets the reality needs and is suitable for Chinese education.}

The Elastic Standard Academic Credit System allows the students to have a $10 \%$ elastic rising of the compulsory standard credit value every term. Take a 4-year degree Jinan University student as an example, if the standard credit value changes from the original 20 to 22 , the student will only need to earn 6 credits (totally 160 credits) to graduate. This program successfully solves some problems such as if the student can't have the $10 \%$ elastic rising, the required 20 credits per term may not be earned resulting in the total 160 credits unable to be achieved so that the student can't graduate in time. The credit value changing to 22 can allow the students make up in the eighth term to earn $x$ credits $(6<x<22)$ to graduate despite some mistakes.

The Elastic Standard Academic Credit System allows the students to have a $10 \%$ elastic rising of the compulsory standard credit value every term and alleviate the learning burden in the eighth term. Still take a 4-year degree Jinan University student as an example that he only needs to earn 6 credits in the eighth term so that the 4 years education time is ensured and the career seeking time and postgraduate entrance exam preparing time are saved, which successfully solves the conflict of the learning burden and reality pressure of career and study. This is a response to the call of the times and suitable for Chinese education condition.

In the general background of the increasing enrollment in the higher education in China, the differences of the learning ability, cultural background are enlarged. To ensure that the students can adapt to the different study requirements, schedules and interests so that they can graduate with a relatively high training effect, the university needs to take a flexible teaching management system. The Elastic Standard Academic Credit System allows the students to have a $10 \%$ elastic rising of the compulsory standard credit value every term so that they can extend or shorten the learning time in a controllable range (3.5-5.5 academic years), which shows great respect to the students individual differences and is suitable to teach students in accordance with their aptitude in distributary teaching stratagem. Also the quality of the talent cultivation is ensured and the reality requirement is satisfied effectively.

\section{References}

[1] Liu, Renhuai. The Research and Practice of Standard Credit System. [J]. China University Teaching, 2004, (3):41-43.

[2] Liu, Zhanzhu. The Exploration and Practice of the Elastic Credit System. [J]. Social Sciences Review, 2007, (5):133-135.

[3] Ma, Sai. The Historical Track of the Creation and Development of the Credit System in Harvard University_-A Concurrent Discussion on the Social Background of the Creation and Development of the Credit System in the United States. [J]. 
Higher Education Exploration, 2009, (1):70-75.

[4] Li, Weiyan, etc. The Misunderstanding and Countermeasure Research in the Revolution of the Credit System. [J]. Journal of Higher Education, 2005, (1):74-77. 